\title{
Sustainability in dialysis therapy: Japanese local and global challenge
}

Kei Nagai ${ }^{*}$ D, Katherine Barraclough ${ }^{2},{\text { Atsushi } \text { Ueda }^{3} \text { and Norihiro Itsubo }}^{4}$

\begin{abstract}
Human-induced climate change is considered the greatest health threat of the 21st century. The health effects of climate change are becoming increasingly apparent, and there is substantial evidence indicating increased risk of kidney injury due to heat illness and other climate change-related meteorological abnormalities. On the other hand, healthcare itself is responsible for environmental burdens and has been estimated to generate between 3 and 10\% of total national $\mathrm{CO}_{2}$ equivalent emissions. Dialysis has been estimated as one of the major contributors to healthcare's carbon footprint. Especially in Australia and the UK, nations that have high awareness regarding environmental research, "Green Nephrology" has emerged as a new discipline. From both of these countries, a series of papers have been produced outlining the carbon footprint of hemodialysis, the results of surveys of specialists' awareness of environmental issues, and proposals for how to save resources in dialysis therapy. Following on from this, several national and international nephrology societies have committed themselves to a range of initiatives aiming at "greening" the kidney sector. In Japan, where water and electricity supplies currently are stable, we occasionally are reminded of the potential for shortages of water and energy and of waste disposal problems. These issues particularly come to the fore in times of disasters, when hemodialysis patients need to be evacuated to distant dialysis facilities. Irrespective of the current state of resource availability, however, continuous efforts and the establishment of resource-saving procedures as a part of Japanese culture are highly desirable and would contribute to environmentally friendly healthcare. Japan needs to build awareness of these issues before the country faces a catastrophic situation of resource shortages. This review is intended as a call to action regarding environmental sustainability in kidney healthcare in Japan and the world.
\end{abstract}

Keywords: Hemodialysis, Peritoneal dialysis, Carbon footprint, Chronic kidney disease, Heat illness

\section{Background}

Human-induced climate change is considered the greatest health threat of the 21 st century. The average annual temperature in the world has risen at a rate of $0.72{ }^{\circ} \mathrm{C}$ per 100 years since the latter half of the 19th century [1]. By the end of this century, global average annual temperature is expected to rise by a further $0.3-1.7^{\circ} \mathrm{C}$ if we urgently and fully reduce Greenhouse gas (GHG) emissions, versus $2.6-4.8$ if we continue with business as

\footnotetext{
* Correspondence: knagai@md.tsukuba.ac.jp

'Department of Nephrology, Faculty of Medicine, University of Tsukuba, Tsukuba, Japan

Full list of author information is available at the end of the article
}

usual [1]. A temperature rise near the upper end of this range is not likely to be compatible with continuing human health and prosperity or indeed civilization as we know it. Notably, the magnitude of temperature increase is greater in countries at higher latitudes like Japan compared to those closer to the equator [2]. The average annual temperature in Japan has seen repeated fluctuations but overall has risen by $1.2^{\circ} \mathrm{C}$ per 100 years since the beginning of the industrial era [2]. In the 21st century, Japan is predicted to experience further temperature rise of 0.5 to $1.7^{\circ} \mathrm{C}$ if maximum efforts are made to reduce GHG emissions versus 3.4 to $5.4^{\circ} \mathrm{C}$ if we continue to live as usual. Consequent to the increasing temperature 
from climate change, heavy rains and floods have been increasing, while the number of rainy days has been decreasing [2]. Although there are some disagreements by people in industry, and some individuals who appear to be unconcerned with climate change, there is consensus among the scientific community and growing understanding among the public that climate change is in fact an existential threat and that extreme weather will continue to increase in Japan, as in most other world regions. Moreover, environmental problems are sometimes difficult for medical professionals to understand in the clinical setting. In daily practice, medical professionals rarely consider the direct effect of greenhouse gas emissions on their patients. In turn, climate change is expected to have a wide range of adverse effects on human health [3].

\section{Climate change and kidney disease}

Climate change has been shown to impact kidney health [4-6] (Fig. 1). The pathways linking climate change with kidney health can be either direct or indirect [4]. For instance, heatwaves directly create risks of acute kidney injury (AKI) and nephrolithiasis because extreme heat increases the insensible loss of body water and salt. This loss can lead to fluid deficit, vasoconstriction, reduced kidney perfusion, and a compensatory reduction in urine volume. In turn, this can lead to AKI and/or urinary supersaturation with stone-forming salts and kidney stone formation [6,7]. Extreme heat combined with strenuous work and water deficit also have been shown to correlate with early-onset chronic kidney disease (CKD), although there is still controversy regarding whether heat is the primary driver of CKD in these cases or an exacerbator of damage caused via an alternative mechanism $[6,8,9]$. Indirect risks are mediated through pathways such as increased frequencies or magnitudes of storms, floods, or droughts, and effects on social structures such as decreases in habitable areas and increases in ethnic conflicts $[4,5]$. In turn, kidney injury can be incurred by altered distribution and prevalence of vectorborne diseases such as malaria and dengue, water shortage, pollution, poor hygiene, and climate-induced disruptions to healthcare provision.

While numerous epidemiological studies from various world regions have investigated the association between ambient temperature and morbidity including with respect to kidney function [10-15], the academic evidence for a relationship between temperature and kidney injury in Japan remains sparse. It is known that the annual number of deaths from heat stroke has risen sharply in Japan from fewer than 200 in the 1990s to approximately 1800 in the decade beginning 2010 [16]. Responding to this change, the number of Japanese language papers discussing heat stroke has increased steadily (Fig. 2A). In contrast, the number of medical journal publications regarding climate change, regardless of kidney disease, has increased only slowly in Japan and overall has remained low compared to the rest of the world (Fig. 2B-D). This observation implies that the Japanese medical community still lacks awareness of the links between climate change and health hazards; indeed, a certain percentage of Japanese healthcare professionals still consider environmental problems as "Fire on the other side of the river" (idiomatically, "None of my business").

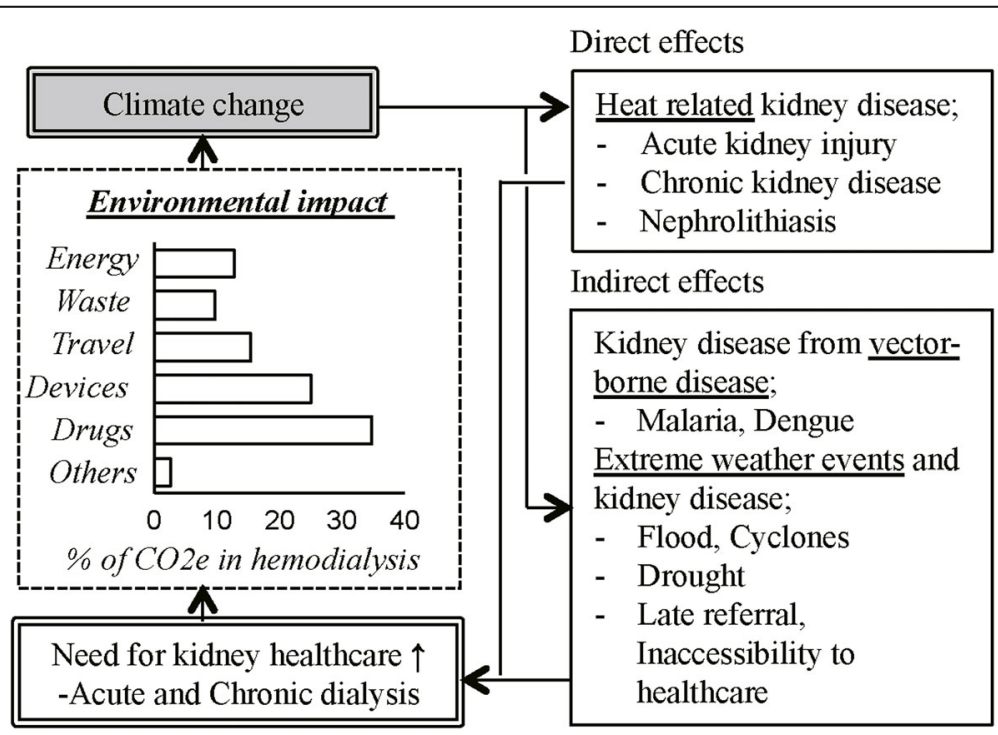

Fig. 1 Cycle of climate change, kidney disease, and healthcare. We propose the concept of a "vicious cycle" among climate change, rising kidney disease burden, the increased need for kidney healthcare services, and accelerated greenhouse gas emissions resulting in rising temperatures. The environment impact was estimated in the previous study [29] 


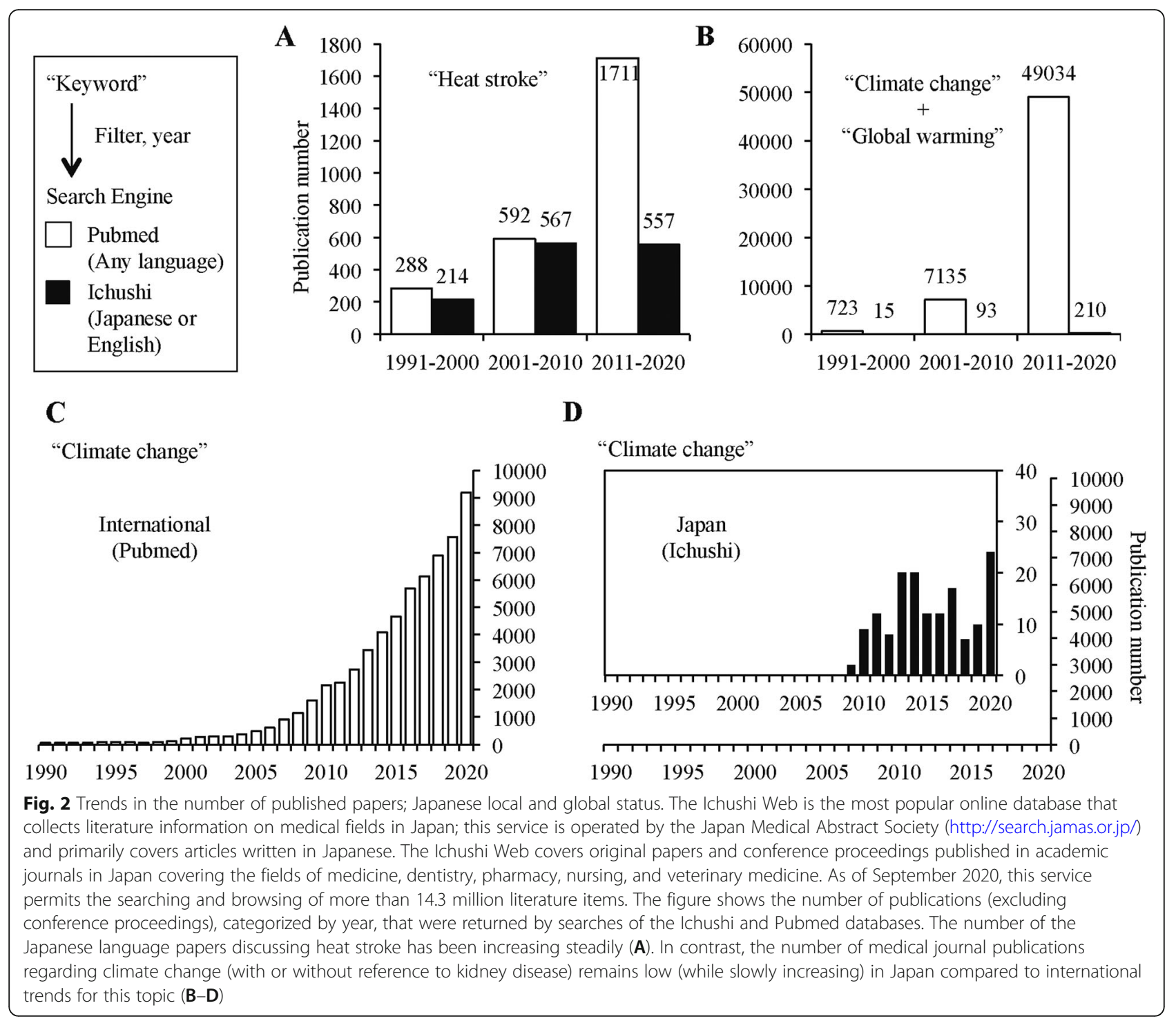

\section{Kidney healthcare is responsible for environmental burdens}

Compared to the impacts of environmental changes on health, the impacts of healthcare on our climate and the environment more broadly have received less attention [17]. However, there is gradually increasing recognition that healthcare is responsible for substantial carbon emissions and that it is therefore accelerating climate change. Country-level studies in the UK [18], the USA [19, 20], Canada [21], Japan [22], China [23], and Australia [24] have reported that healthcare sector emissions contribute between 3 and $10 \%$ of the total carbon footprint in these countries. A recent report has suggested that if global healthcare were a country, it would be the fifth-largest emitter on the planet [25]. We propose the existence of a "vicious cycle," with climate change leading to rising disease burden, increased need for healthcare services, and accelerated greenhouse gas emissions from healthcare, which then lead to further temperature rise (Fig. 1).

Among healthcare services, therapy for end-stage kidney disease has been estimated to be a major contributor to healthcare's carbon footprint [26-28]. As the number of patients with end-stage kidney disease continues to increase, resource-hungry dialysis processes proliferate [26]. Several investigators have attempted analyses of the carbon footprint created by dialysis therapy (Table 1 ). The carbon footprint of conventional hemodialysis (HD) in Australia has been estimated to be $10.2 \mathrm{t} \mathrm{CO}_{2}$ equivalent $\left(\mathrm{CO}_{2} \mathrm{e}\right)$ per patient per year [29]. This is more than two-thirds of the mean annual per capita $\mathrm{CO}_{2}$ emission estimate in Australia. Interestingly, the largest share of carbon emissions in this study arose from pharmaceuticals and medical equipment, with building energy use, water, and waste making substantially smaller contributions [29]. In contrast, the overall carbon footprint of 
Table 1 Representative carbon footprint studies, green surveys, and position papers in kidney healthcare

\begin{tabular}{|c|c|c|}
\hline $\begin{array}{l}\text { Author, } \\
\text { publication year }\end{array}$ & Summary of findings, annotation & Reference \\
\hline Connor, 2010 & $\begin{array}{l}\text { In the Dorset Renal Service, which covers a population of } 865,000 \text {, activity data were collected for building energy } \\
\text { use, travel, and procurement. The provision of hemodialysis and peritoneal dialysis to } 277 \text { patients results in } 1,965 \mathrm{t} \\
\mathrm{CO}_{2} \mathrm{e} \text {, equating to } 7.1 \mathrm{tCO}_{2} \mathrm{e} \text { per dialysis patient. }\end{array}$ & [27] \\
\hline Connor, 2011 & $\begin{array}{l}\text { This study compared carbon footprints of the differing modalities and treatment regimens of maintenance } \\
\text { hemodialysis. In home hemodialysis, dialyzing more frequently and for longer hours compared to in-center pa- } \\
\text { tients tended to increase emissions. }\end{array}$ & [28] \\
\hline Lim, 2013 & $\begin{array}{l}\text { In Victoria, Australia, the annual per-patient carbon footprint of satellite hemodialysis was calculated to be } 10.2 \mathrm{t} \\
\mathrm{CO}_{2} \mathrm{e} \text {, based on activity data in } 2011 \text {. }\end{array}$ & [29] \\
\hline Chen, 2017 & $\begin{array}{l}\text { The carbon footprint of } 68 \text { subjects receiving peritoneal dialysis treatment was examined. Packaging consumption } \\
\text { constituted the largest fraction of the overall carbon footprint, which totaled } 1.4 \mathrm{t} \text { CO2e per patient per year. }\end{array}$ & {$[30]$} \\
\hline Nansai, 2020 & $\begin{array}{l}\text { Carbon footprint of general healthcare in Japan was estimated by environmental input-output (EIO) and disaggre- } \\
\text { gated to obtain the kidney disease-related value. Studies from other countries and international ElO investigations } \\
\text { do not disaggregate by kidney-care section-specific data. National (Japanese) carbon footprint for "renal, urethral, } \\
\text { and reproductive disease" was } 2.12 \text { million metric tons } \mathrm{CO}_{2} \mathrm{e} \text {. }\end{array}$ & [22] \\
\hline Pollard, 2014 & $\begin{array}{l}\text { This study used a bottom-up consumption model to estimate the carbon footprint of acute care with dialysis ma- } \\
\text { chines in the UK, primarily counting electricity use. For a typical patient in a critical care unit (CCU) for } 2 \text { days, a } \\
\text { renal replacement machine consumed } 9.60 \mathrm{kWh} / 200 \mathrm{~W} \text {. }\end{array}$ & [39] \\
\hline Bendine, 2020 & $\begin{array}{l}\text { Monthly eco-reporting was implemented in NephroCare centers in France in 2005. The indicators included electri- } \\
\text { city and water consumption as well as the generation of care-related waste. During the 2005-2018 study period, } \\
\text { power and water consumption declined by } 30 \% \text { and 52\%, respectively. Waste decreased from } 1.8 \text { to } 1.1 \mathrm{~kg} \text { per } \\
\text { session. }\end{array}$ & [40] \\
\hline Conner, 2010 & $\begin{array}{l}\text { A Green Nephrology survey of } 58 \text { kidney care units in England, Scotland, and Wales was conducted to support a } \\
\text { clinical transformation to lower carbon kidney healthcare by identifying fruitful areas for attention. }\end{array}$ & [36] \\
\hline Barraclough, 2019 & $\begin{array}{l}\text { A green nephrology survey was conducted across } 83 \text { kidney healthcare units in Victoria, Australia. Nurse unit } \\
\text { managers of public dialysis facilities responded to } 107 \text { questions relevant to the environmental sustainability of } \\
\text { dialysis services. }\end{array}$ & [37] \\
\hline Moura-Neto, 2019 & This paper was a call-to-action for sustainability in dialysis in Brazil. & {$[32]$} \\
\hline Piccoli, 2020 & $\begin{array}{l}\text { A position statement was developed by the Italian Society of Nephrology, focusing primarily on dialysis } \\
\text { management. It identified ten first affordable actions. }\end{array}$ & [33] \\
\hline
\end{tabular}

peritoneal dialysis (PD) has been estimated as only $1.4 \mathrm{t}$ $\mathrm{CO}_{2} \mathrm{e}$, a value that is substantially lower than that of HD [30]. However, in this study, the carbon emissions impact of pharmaceutical use and of transportation of PD fluids from the point of manufacture to the point of care were not considered; as a result, $80 \%$ of the carbon footprint of PD was attributed to packing materials such as plastic bags and cardboard. Therefore, more precise assessments are needed to determine whether PD is more environmentally friendly than HD.

\section{What are nephrologists doing to achieve "greener" dialysis?}

Clearly, kidney care and dialysis have negative environmental impacts, ranging from the local to the global scale. Especially in Australia and the UK, countries that have high awareness of environmental issues, advocates of "Green Nephrology" have promoted environmentallyfriendly practices for dialysis, actively produced a series of papers to demonstrate the carbon footprint of kidney healthcare, and distributed the results of surveys investigating specialists' awareness regarding the conservation of resources in dialysis therapy (Table 1). Following on from such individual Green Nephrology programs, several international and nationwide nephrology societies have committed to a range of initiatives aimed at "greening" kidney healthcare [6,31]. The European Renal Association - European Dialysis and Transplant Association has organized a number of green nephrology meetings involving representatives of national and regional nephrology groups and industry stakeholders [31]. During Kidney Week 2018, a first global meeting on Green Nephrology was held with the support of the International Society of Nephrology. Subsequently, both Brazil [32] and Italy [33] have taken action to expand local activities in support of green dialysis. In Japan, however, promotions and initiatives for environmentally friendly kidney healthcare and dialysis therapy have not yet developed. Given Japan's status as the country harboring the second largest dialysis population in the world, practical and cultural shifts in kidney care (e.g., the establishment of resource-saving dialysis processes) are needed. In context of the need of financial resources to realize eco-friendly dialysis, some capital investment may be required for solar power generation and water reuse $[6,26]$. However, these activities are just a part 
and complementary to Green Nephrology. The medical care we ultimately aim for is one that does not burden the economy. We are convinced of achieving ecofriendly renal health care with cost-effective way such as preventing renal diseases, stopping unnecessary medications and excessive dialysis prescriptions, and reuse possible dialysis plastic supplies.

\section{Experience of resource shortage during natural disasters in Japan}

In recent years, heavy rainfall has been on the rise, and there are concerns about extreme weather-related disasters. In Japan, we have occasionally (and suddenly) become aware of shortages of water and energy and of waste disposal problems, particularly in the context of major disasters such as Typhoon Faxai in September 2019 and Hagibis in October 2019. Particularly, Hagibis caused more than 90 deaths and left more than 270,000 households across the country without power. Although no official statement has been issued, some local press reported that hundreds of patients on chronic dialysis needed to be evacuated due to water shortages and power blackouts. Another kind of disaster, earthquakes (e.g., the Great East Japan Earthquake in 2011 [34] and the Han-Shin Awaji Earthquake in 1995 [35]), are not extreme weather-related events, but do occur more frequently in Japan than elsewhere and do force HD patients to evacuate to distinct dialysis facilities, in part due to shortages of water and electricity. These experiences could serve as an opportunity for kidney healthcare professionals to consider what options will be available if/when climate-related disasters hit and dialysis materials and resources are depleted. We need to be aware of catastrophic situations that will lead to resource shortages even in Japan, which is no exception to these worldwide concerns, and ensure that thorough preparedness planning for disasters is undertaken.

\section{Conclusion: How can kidney healthcare professionals prepare for the future?}

As discussed above, Japan, like most other world regions, is likely to see increasing health impacts from climate change. There is moral imperative for Japan to consider ways to achieve more planet friendly dialysis therapy and to undertake preparedness planning for climate changerelated emergencies. Possible actions to take include encouraging staff and patients to save water and energy where possible and dialysis units to install water- and energy-saving systems [6]. It would be also environmentally beneficial to evaluate the weight and types of waste generated from different dialysis machines and consumables sets and to undertake efforts to optimize waste segregation and recycling [6].
It is an undeniable fact that we do not have any precise measure of the $\mathrm{CO}_{2}$ emissions and other environmental impacts of dialysis practices in Japan. Surveys of environmental attitudes and knowledge of greener dialysis processes in Japan are needed to understand the current situation domestically, as has been done in other countries [6, 36, 37]. In the context of kidney healthcare, including dialysis, various countries differ considerably in their practice patterns and geographical issues. In Japan, over $97 \%$ of dialysis is conducted as in-center HD, supplemented by much lower percentages of patients treated by home dialysis and by unsatisfactorily low numbers of transplantation surgeries [38]. Moreover, Japan is an island country and has low food and energy self-sufficiency, making the nation dependent on overseas resources. Therefore, it is not easy to apply research results obtained from other countries, which have different practice patterns and resource management compared to Japan. Research specific to the Japanese context must be conducted.

\section{Abbreviations \\ GHG: Greenhouse gas; RCP: Representative concentration pathway; CKD: Chronic kidney disease; HD: Hemodialysis; $\mathrm{CO}_{2} \mathrm{e}$ : $\mathrm{CO}_{2}$ equivalent; PD: Peritoneal dialysis; CCU: Critical care unit}

\section{Acknowledgements \\ John Agar (Barwon Health, Geelong, Australia) read and advised about the content of the manuscript.}

Authors' contributions

KN wrote the first draft of the manuscript, and KB supervised it. AU and $\mathrm{NI}$ read and advised about the content of the manuscript of the final version. All authors read and approved the final manuscript.

Funding

This article was supported, in part, by JSPS Grant No. 18KK0431 and by the Japanese Association of Dialysis Physicians Grant No. 2019-1.

Availability of data and materials

Not applicable

\section{Declarations}

Ethics approval and consent to participate

Not applicable

Consent for publication

The authors confirm for publication.

Competing interests

The authors declare that the review/research work was conducted in the absence of any commercial or financial relationships that could be construed as a potential conflict of interest.

\section{Author details}

${ }^{1}$ Department of Nephrology, Faculty of Medicine, University of Tsukuba Tsukuba, Japan. ${ }^{2}$ Department of Nephrology, Royal Melbourne Health, Parkville, Australia. ${ }^{3}$ Department of Nephrology, Hitachi General Hospital, 2-1-1 Jonan-cho, Hitachi, Ibaraki 317-0077, Japan. ${ }^{4}$ Faculty of Environmental and Information Studies, Tokyo City University, 3-3-1 Ushikubo-nishi, Tsuzuki-ku, Yokohama, Kanagawa 224-8551, Japan. 
Received: 1 March 2021 Accepted: 1 July 2021

Published online: 22 July 2021

\section{References}

1. Intergovernmental Panel on Climate Change (IPCC). AR5 Synthesis Report: Climate Change 2014

2. Japan Meteorological Agency (2016) Climate change monitoring report 2016 (in Japanese).

3. Watts N, Adger WN, Ayeb-Karlsson S, Bai Y, Byass P, et al. The Lancet Countdown: tracking progress on health and climate change. Lancet. 2017; 389(10074):1151-64.

4. Watts N, Adger WN, Agnolucci P, Blackstock J, Byass P, et al. Health and climate change: policy responses to protect public health. Lancet. 2015: 386(10006):1861-914.

5. Barraclough KA, Blashki GA, Holt SG, Agar JWM. Climate change and kidney disease-threats and opportunities. Kidney Int. 2017;92(3):526-30.

6. Barraclough KA, Agar JWM. Green nephrology. Nat Rev Nephrol. 2020;16(5): 257-68

7. Fakheri RJ, Goldfarb DS. Association of nephrolithiasis prevalence rates with ambient temperature in the United States: a re-analysis. Kidney Int. 2009; 76(7):798.

8. Sorensen C, Garcia-Trabanino R. A New Era of Climate Medicine Addressing Heat-Triggered Renal Disease. New Engl J Med. 2019;381(8):6936.

9. Glaser J, Lemery J, Rajagopalan B, Diaz HF, Garcia-Trabanino R, et al. Climate Change and the Emergent Epidemic of CKD from Heat Stress in Rural Communities: The Case for Heat Stress Nephropathy. Clin J Am Soc Nephrol. 2016;11(8):1472-83.

10. Fletcher BA, Lin S, Fitzgerald EF, Hwang S-A. Association of Summer Temperatures With Hospital Admissions for Renal Diseases in New York State: A Case-Crossover Study. Am J Epidemiol. 2012;175(9):907-16.

11. Kim SE, Lee H, Kim J, Lee YK, Kang M, et al. Temperature as a risk factor of emergency department visits for acute kidney injury: a case-crossover study in Seoul. South Korea Environ Health. 2019;18(1):55

12. Lim $Y-H$, So $R$, Lee $C$, Hong $Y-C$, Park $M$, et al. Ambient temperature and hospital admissions for acute kidney injury: A time-series analysis. Sci Total Environ. 2018:616-617:1134-8.

13. Knowlton K, Rotkin-Ellman M, King G, Margolis HG, Smith D, et al. The 2006 California heat wave: impacts on hospitalizations and emergency department visits. Environ Health Perspect. 2009;117(1):61-7.

14. Hansen AL, Bi P, Ryan P, Nitschke M, Pisaniello D, et al. The effect of heat waves on hospital admissions for renal disease in a temperate city of Australia. Int J Epidemiol. 2008;37(6):1359-65.

15. Borg M, Bi P, Nitschke M, Williams S, McDonald S. The impact of daily temperature on renal disease incidence: an ecological study. Environ Health. 2017;16(1):114

16. Ministry of the Environment, Government of Japan. Heat Stroke Environmental Health Manual 2018. https://www.wbgt.env.go.jp/en/

17. Lenzen M, Malik A, Li M, Fry J, Weisz H, et al. The environmental footprint of health care: a global assessment. Lancet Planet Health. 2020:4(7):e271-9.

18. Pencheon D. Developing a sustainable health care system: the United Kingdom experience. Med J Aust. 2018:208(7):284-5.

19. Chung JW, Meltzer DO. Estimate of the carbon footprint of the US health care sector. JAMA. 2009:302(18):1970-2.

20. Eckelman MJ, Sherman J. Environmental Impacts of the U.S. Health Care System and Effects on Public Health. PLoS One. 2016:11(6):e0157014.

21. Eckelman MJ, Sherman JD, MacNeill AJ. Life cycle environmental emissions and health damages from the Canadian healthcare system: An economicenvironmental-epidemiological analysis. PLoS Med. 2018;15(7):e1002623.

22. Nansai K, Fry J, Malik A, Takayanagi W, Kondo N. Carbon footprint of Japanese health care services from 2011 to 2015. Resour Conserv Recycl. 2020;152:104525.

23. Wu R. The carbon footprint of the Chinese health-care system: an environmentally extended input-output and structural path analysis study. Lancet Planet Health. 2019;3(10):e413-9.

24. Malik A, Lenzen M, McAlister S, McGain F. The carbon footprint of Australian health care. Lancet Planet Health. 2018;2(1):e27-35.

25. Health Care Without Harm. Health Cares's Climate Footprint. 2019. https:// noharm-global.org/sites/default/files/documents-files/5961/HealthCa resClimateFootprint_090619.pdf
26. Agar JW. Green dialysis: the environmental challenges ahead. Semin Dial. 2015;28(2):186-92

27. Connor A, Lillywhite $\mathrm{R}$, Cooke MW. The carbon footprint of a renal service in the United Kingdom. QJM. 2010;103(12):965-75.

28. Connor A, Lillywhite R, Cooke MW. The carbon footprints of home and incenter maintenance hemodialysis in the United Kingdom. Hemodial Int. 2011;15(1):39-51.

29. Lim AE, Perkins A, Agar JW. The carbon footprint of an Australian satellite haemodialysis unit. Aust Health Rev. 2013;37(3):369-74.

30. Chen M, Zhou R, Du C, Meng F, Wang Y, et al. The carbon footprints of home and in-center peritoneal dialysis in China. Int Urol Nephrol. 2017;49(2): 337-43

31. Blankestijn PJ, Arici M, Bruchfeld A, Capasso G, Fliser D, et al. ERA-EDTA invests in transformation to greener health care. Nephrol Dial Transplant. 2018;33(6):901-3.

32. Moura-Neto JA, Barraclough K, Agar JWM. A call-to-action for sustainability in dialysis in Brazil. J Bras Nefrol. 2019;41(4):560-3.

33. Piccoli GB, Cupisti A, Aucella F, Regolisti G, Lomonte C, et al. Green nephrology and eco-dialysis: a position statement by the Italian Society of Nephrology. J Nephrol. 2020;33(4):681-98.

34. Masakane I, Akatsuka T, Yamakawa T, Tsubakihara Y, Ando R, et al. Survey of dialysis therapy during the Great East Japan Earthquake Disaster and recommendations for dialysis therapy preparation in case of future disasters. Renal Replac Ther. 2016;2:48.

35. Fukagawa M. Nephrology in Earthquakes: Sharing Experiences and Information. Clin J Am Soc Nephrol. 2007;2(4):803.

36. Connor A, Mortimer F. The green nephrology survey of sustainability in renal units in England, Scotland and Wales. J Ren Care. 2010:36(3):153-60.

37. Barraclough KA, Gleeson A, Holt SG, Agar JW. Green dialysis survey: Establishing a baseline for environmental sustainability across dialysis facilities in Victoria, Australia. Nephrology. 2019;24(1):88-93.

38. Hanafusa N, Fukagawa M. Global Dialysis Perspective: Japan. Kidney360. 2020;1(5):416.

39. Pollard AS, Paddle JJ, Taylor TJ, Tillyard A. The carbon footprint of acute care: how energy intensive is critical care? Public Health. 2014;128(9):771-6.

40. Bendine G, Autin F, Fabre B, Bardin O, Rabasco F, et al. Haemodialysis therapy and sustainable growth: a corporate experience in France. Nephrol Dial Transplant. 2020;35(12):2154-60.

\section{Publisher's Note}

Springer Nature remains neutral with regard to jurisdictional claims in published maps and institutional affiliations.
Ready to submit your research? Choose BMC and benefit from:

- fast, convenient online submission

- thorough peer review by experienced researchers in your field

- rapid publication on acceptance

- support for research data, including large and complex data types

- gold Open Access which fosters wider collaboration and increased citations

- maximum visibility for your research: over $100 \mathrm{M}$ website views per year

At BMC, research is always in progress.

Learn more biomedcentral.com/submissions 